\title{
Pandemia, distanciamento social e academia - Dançando no escuro 20 anos depois
}

\author{
Prof. Dr. Hélio ARThur Reis IrigaraY ${ }^{1}$ \\ ${ }^{1}$ Fundação Getulio Vargas / Escola Brasileira de Administração Pública E de EMPresas, Rio de Janeiro - RJ, Brasil
}

Em 11 de março deste ano, a Organização Mundial da Saúde (OMS) declarou que o mundo enfrentava uma nova pandemia (WHO, 2020), desta vez causada pelo SARS-CoV-2 (severe acute respiratory syndrome coronavirus 2), o qual é o agente etiológico da COVID-19, uma doença infecciosa de caráter respiratório, para qual não há nem vacina nem tratamento comprovadamente eficaz (SINGHAL, 2020).

As medidas de prevenção indicadas são lavagem de mãos com água e sabão, higienização das mãos com preparações alcoólicas, uso de máscara facial e distanciamento social, cujo objetivo é diminuir a interação e a proximidade entre pessoas numa comunidade, na qual alguns indivíduos infectados, mas ainda não identificados, podem transmitir a doença (HE, DENG e LI, 2020).

Entretanto, segundo a Pesquisa Nacional de Amostra por Domicílio Contínua (Pnad), de 2018, 31,1 milhões de brasileiros vivem em domicílios sem acesso a água fornecida por meio da rede geral de abastecimento; 74,2 milhões, em áreas sem coleta de esgoto; 5,8 milhões não têm banheiro em casa; e 11,6 milhões habitam imóveis densamente povoados, ou seja, com mais de três moradores por dormitório (IBGE, 2020). Como praticar o distanciamento social nestas condições? A política sugerida aplica-se a uma minoria economicamente privilegiada.

O mesmo pode-se dizer das atividades econômicas: $23 \%$ dos brasileiros já perderam totalmente sua fonte de renda e $17 \%$ tiveram uma redução do ganho mensal (CNI, 2020).

Mas, mesmo para aqueles que não se enquadram nestas categorias - como a maioria de nós professores e acadêmicos - de que forma as atividades profissionais mudaram?

Antes de mais nada, temos de reconhecer que somos privilegiados: exercemos uma profissão valorizada socialmente, temos direitos trabalhistas assegurados, o que nos possibilita refletir sobre os desafios que as aulas síncronas mediadas pela tecnologia nos impõem, bem como sobre o tipo de ensino e relações de trabalho que desejamos.

De uma hora para outra vimos nossas aulas e encontros acadêmicos migrarem totalmente para o ambiente digital, o que nos obrigou a aprender novos sistemas, repensar métodos pedagógicos, reescrever nossos planos de aula, incluir novos conteúdos, numa velocidade e senso de urgência sem precedentes.

Nossas tarefas cotidianas cresceram exponencialmente e, mais do que isso, passaram a demandar de nós habilidades nas quais, nem sempre, éramos proficientes. Vimo-nos obrigados a gerenciar nossas ansiedades e, também, as dos nossos alunos, pares, superiores, colegas administrativos. Tudo isso sob uma intensa pressão organizacional por resultados de desempenho e pelo fantasma da incerteza futura. Em muitas instituições de ensino, os docentes são avaliados ao final de cada disciplina e, frequentemente, a insegurança com as ferramentas tecnológicas, também por parte dos alunos, e o gerenciamento do tempo de aula podem se tornar fatores que comprometam a qualidade percebida do encontro. Ademais, em alguns casos, os (as) docentes deparam-se com a ameaça de redução de salários, de carga horária e, até mesmo, com a sinalização do iminente término do contrato de trabalho. Esta nova configuração do mundo do trabalho resultou em uma (sobre)carga emocional.

Dessa forma, os(as) docentes encontram-se, como nunca ocorrera antes, diante da necessidade de repensar e gerenciar a própria carreira, sob o espectro de uma "crise econômica sem precedentes na história" (FMI, 2020) e de ter de barganhar por seus empregos, aceitando realizar atividades adicionais (treinamentos, reuniões) não remuneradas.

Assim como ocorreu com outras categorias profissionais, que também passaram a trabalhar no sistema de home office, o distanciamento social obrigou professores e acadêmicos a lidarem com a frágil fronteira que separava suas vidas pessoal e 
profissional; a equilibrarem suas múltiplas identidades dentro do seu espaço doméstico, tendo sobre os ombros uma pesada carga de trabalho físico e emocional. Agora, a casa é o local de trabalho, não mais de refúgio e descanso. A residência, ora propriedade privada, foi incorporada e se tornou uma empresa de sociedade anônima.

O distanciamento social ainda exacerbou o lado patriarcal e machista da sociedade brasileira; uma vez que o confinamento das pessoas à esfera privada do lar agravou os atos de violência contra as mulheres (MODELLI, 2020) e a população LGBTQIA+ (LISBOA, 2020). A casa, já descrita como a antípoda do trabalho, revelou-se, mais uma vez, um espaço no qual as mulheres deparam-se com a maior sobrecarga de trabalho não remunerado. Aparentemente, esta realidade não é característica apenas das classes socioculturais menos favorecidas, há evidências de que o trabalho das acadêmicas, que já foi objeto de estudo anteriormente (por exemplo, Miranda et al., 2013), ficou ainda mais comprometido neste primeiro trimestre de 2020, uma vez que a submissão de artigos acadêmicos por mulheres caiu 12\% (CÂNDIDO e CAMPOS, 2020).

Outro impacto do distanciamento social a ser considerado é a "desertificação" do espaço físico das universidades e faculdades. Ver nossos escritórios, salas de aula, bibliotecas e corredores vazios (sem ser período de férias) é angustiante. Por mais que as redes sociais, aplicativos e soluções digitais viabilizem contatos, aulas, reuniões e orientações, onde estão todos? Onde estamos nós?

O distanciamento social gera a sensação de um sofrimento sem fim, de estarmos numa escuridão, a única esperança jaz num passado romantizado.

Todo esse cenário aproxima-nos de Selma Jezková, a protagonista do filme Dançando no Escuro, escrito e dirigido por Lars Von Trier, lançado há vinte anos.

A angustiante trama desenrola-se na década de 1960, nos Estados Unidos, e retrata a vida de Selma Jezková, mãe solteira de Gene, um menino de 12 anos, portadora de uma doença hereditária degenerativa que causa uma cegueira consumidora e progressiva e que eventualmente será desenvolvida por seu filho.

Com o objetivo de conseguir uma cirurgia para o filho, emigra para os EUA, onde passa a morar em um trailer alugado, trabalhar como metalúrgica numa fábrica, engajar-se em ensaios musicais no teatro e sonhar com os musicais de Hollywood.

Apesar desse argumento novelesco, o filme em questão difere-se das novelas latino-americanas e das comédias musicais estadunidenses, pois nem tudo acaba bem. A protagonista não é uma princesa a ser salva por um príncipe encantado. Ciente de sua precária condição de saúde e com a acuidade visual cada vez mais comprometida, Selma luta por sua dignidade diuturnamente, sem baixar a guarda ou incorporar o papel melodramático de "donzela indefesa". Pelo contrário, em nenhum momento se vale destas condições limitadoras para despertar pena das pessoas à sua volta, segue lutando diuturnamente para superar tais barreiras e proporcionar um futuro diferente ao filho.

Em virtude de sua doença, Selma envolve-se em um acidente de trabalho e acaba por quebrar uma máquina, o que resulta em sua demissão. Neste momento, seu amigo Jeff se dá conta de que ela enxerga com muita dificuldade. Selma, sem a menor autopiedade, afirma que "nos musicais não existem problemas", e então canta para ele "já vi tudo o que precisava ver na vida."

A vida da protagonista encaminha-se a um trágico rumo quando, ludibriada por seu amigo Bill, com quem trocara confidências, é roubada.

Bill prometera nunca contar a ninguém sobre o real estado de saúde de Selma; ela, por sua vez, nunca revelaria que o amigo policial, para satisfazer todos os desejos consumistas da esposa, endividara-se e falira.

Num ato premeditado, valendo-se da limitação visual de Selma, Bill rouba-Ihe todo o dinheiro que ela economizara. Selma tenta reaver o dinheiro, explica ao amigo que precisa pagar o médico, pois, em poucos dias, estará completamente cega, mas o amigo está decidido a não Ihe devolver todas as suas economias. Frente à insistência de Selma, Bill começa a gritar que está sendo assaltado, toma uma arma e acaba por ser baleado, mas não morre. Ferido, implora a Selma que o mate, para que sua esposa jamais descubra a verdade sobre a sua real situação financeira. Completamente transtornada, a imigrante faz o que o amigo pede. Bill morre. Selma é presa, julgada e condenada à forca, sem nunca revelar o segredo de Bill e a verdadeira origem do dinheiro, o que poderia ter-lhe salvado a vida. Apesar de tudo, foi fiel à sua verdade e ao amigo até o fim.

Trier usa Selma como uma metáfora para criticar o sistema estadunidense, desmascarar o American Dream e sua pressuposta meritocracia, bem como denunciar uma sociedade e um sistema onde os fracos e honestos não têm vez. 
Se, inicialmente, era uma empresa que sequestrava os sonhos da imigrante tcheca, na segunda parte do filme, ela torna-se vítima do sistema jurídico estadunidense: sem dinheiro para pagar um advogado, é defendida por um profissional indicado pela Corte. Nesta sequência, Trier deixa a personagem sem fala; enquanto o promotor, com boa retórica, convence o júri.

Quanto a nós, valemo-nos de Selma como metáfora dos professores, professoras e acadêmicos neste momento de distanciamento social e home office. Similarmente à protagonista na primeira parte do filme, comportamo-nos como operários do saber e do ensino, cujos artigos e aulas são produzidos numa linha de montagem. Acreditamos, ou fingimos acreditar (GOFFMAN, 1959), na meritocracia (que um dia todos os nossos esforços serão reconhecidos) e na lógica produtivista; naturalizamos as expectativas de que intensifiquemos nossa produção acadêmica (já que estamos em casa), adaptemo-nos aos novos modelos de aula e sejamos, no mínimo, excelentes. Assim, tornamo-nos os sujeitos pós-modernos do desempenho descritos por Han (2019). Estamos presos e vigilantes dentro de nós mesmo o tempo todo, sujeitando-nos a carregar nossa própria prisão.

Assim como Selma, estamos perdendo a visão; a rigor, estamos nos perdendo de vista, ao passo que introjetamos a negatividade do superego, o qual restringe a liberdade do ego, e a substituímos pela projeção do "eu ideal". No limite, estamos competindo conosco e, à medida que o eu ideal revela-se inatingível, consideramo-nos um grande fracasso.

No entanto, também como Selma, mantemo-nos fiéis e honestos aos nossos propósitos de aula e de produções acadêmicas de qualidade. Queremos contribuir para que nossos alunos e alunas sejam capazes de refletir e pensar criticamente; que nossos artigos abram novas veredas no nosso campo de saber e sinalizem possíveis - e melhores - futuros para nossa sociedade e organizações. Contudo, muitas vezes, enfrentamos uma cruzada anti-iluminista, somos ofendidos e condenados por parte da sociedade e seus representantes oficiais, que percebem a ciência e o conhecimento como inimigos nacionais. Todavia nenhuma destas condenações chegam perto da intensidade do nosso autojulgamento inundado de culpa, da sensação de não estarmos produzindo o tanto quanto poderíamos, queríamos, com o ineditismo e relevância que desejamos, tampouco ministrando as aulas com a qualidade que podemos alcançar.

Mais uma vez, da mesma forma que Selma, estamos dançando no escuro, ensimesmados com os dias que estão por vir, questionando-nos sobre a nossa capacidade de proposições de novas ideias, teorias e reflexões e, até mesmo, sobre o propósito de nosso papel social e da nossa capacidade de engajamento na academia e na sociedade como um todo.

Como professores e acadêmicos temos de resgatar a razão de ser das universidades, faculdades e instituições de ensino e pesquisa. Estas organizações não podem limitar-se ao papel de empresas com modelos de negócios, cujo único objetivo é a maximização de lucros. Somos centros de pesquisa, geramos saber e conhecimento, contribuímos para o desenvolvimento econômico e social do Brasil. Nosso papel social é (re)pensar nosso país, engajarmo-nos e propor soluções para os problemas nacionais.

Como docentes, não podemos deixar-nos seduzir pelo discurso - e prática - de aulas pirotécnicas mediadas pela tecnologia; é nossa obrigação refletir não apenas sobre as metodologias de ensino, mas, fundamentalmente, sobre os conteúdos de nossos cursos, no sentido de que capacitem nossos alunos e alunas a refletirem e agirem.

Nunca podemos esquecer que as nossas instituições são comunidades, as quais possuem diversas partes interessadas acadêmicos, estudantes, corpo de funcionários administrativos, nossos pares, outras instituições, associações, órgãos de classe e governamentais, bem como a sociedade per se-e com as quais devemos elaborar novas formas colaborativas de trabalho.

Este é o desafio que temos pela frente.

Para começarmos esta reflexão, convido a todos a desfrutarem dos textos que compõem esta edição.

Iniciamos com o trabalho de Rubens Mussolin Massa, Raul Beal Partyka e Jeferson Lana, intitulado "Pesquisa e teoria da agência comportamental: uma revisão e agenda de pesquisa", que apresenta o argumento de que a remuneração por desempenho dos executivos, segundo a teoria da agência, é o mecanismo mais utilizado para estimulá-los a tomarem decisões sobre o crescimento e o melhor desempenho da empresa.

Logo a seguir, no artigo "Desvelando o conceito de transparência: seus limites, suas variedades e a criação de uma tipologia", Karina Furtado Rodrigues propõe uma tipologia que conta com quatro subtipos de transparência nas organizações: (1) a transparência plena; (2) a transparência nominal; (3) a transparência condicionada; (4) a transparência na atribuição e gestão de informações sigilosas.

“Organizar na era dos sistemas: as contribuições críticas de Ivan Illich aos estudos organizacionais", escrito por Lucas Casagrande e Nilo Coradini de Freitas, apresenta o pensamento de Ivan Illich e suas contribuições aos estudos organizacionais. 
Já Gean Carlos Tomazzoni e Vânia Medianeira Flores Costa desenvolvem, no artigo "Vínculos organizacionais de comprometimento, entrincheiramento e consentimento: explorando seus antecedentes e consequentes", um modelo de análise das influências dos valores organizacionais nos vínculos de comprometimento, entrincheiramento e consentimento do indivíduo com a organização.

Com o objetivo de traçar um perfil identitário das maiores empresas brasileiras a partir da análise de suas declarações de missão, André Rehbein Sathler e Roberto Campos da Rocha Miranda produziram o artigo "Quem são e o que fazem as empresas brasileiras? Análise das declarações de missão".

"Lukács e a particularidade estética do trabalho assalariado e da mediação da burocracia do Estado em “Eu, Daniel Blake”, uma análise fílmica, é o objeto do ensaio escrito por Bárbara Katherine Faris Biondini, Rossi Henrique Soares Chaves e Janaynna de Moura Ferraz.

Por sua vez, as contradições de um modelo de Responsabilidade Social Corporativa é o tema da pesquisa de Juliana Campos Lopes e Jacques Demajorovic, intitulada "Responsabilidade Social Corporativa: uma visão crítica a partir do estudo de caso da tragédia socioambiental da Samarco".

Em “Planejamento governamental nos municípios brasileiros: em direção a uma agenda de pesquisa”, Luciana Leite Lima, Lizandro Lui, Gianna Vargas Reis Salgado Dias, Luciana Pazini Papi e Diogo Joel Demarco investigam a produção científica sobre o planejamento municipal.

Mara Vogt, Edmery Tavares Barbosa, Marcia Zanievicz da Silva e Arno Paulo Schmitz descrevem os fatores determinantes das diferenças salariais entre os profissionais da contabilidade no Brasil, em "Fatores determinantes das diferenças salariais entre as ocupações da contabilidade".

“O que é ser um acadêmico de administração indígena?" Pergunta de pesquisa de Renan Carlos Klichowski, Marcio Pascoal Cassandre e Wagner Roberto do Amaral, que buscam identificar e analisar quais as compreensões, expectativas e os dilemas presentes nos percursos formativos dos estudantes indígenas dos cursos de administração das universidades estaduais paranaenses.

Já a análise das relações de tempo e da cultura de consumo na modernidade e sua repercussão nas experiências humanas, pela perspectiva crítica da administração, é o tema de "Aceleração, tempo social e cultura do consumo: notas sobre as (im) possibilidades no campo das experiências humanas", escrito por Carlos Victor Leal Aderaldo, Cassio Adriano Braz de Aquino e Maria de Fátima Vieira Severiano.

Em "Locais de mercado, diversidade e exclusão interseccional", Paulo Roberto Chaves Dalpian e Teniza da Silveira discutem como a incidência da interseccionalidade opera dentro de locais de mercado que se apresentam como diversos ou abertos à diversidade - especificamente lugares gays.

A análise da construção das identidades de prostitutas evangélicas que trabalham em uma zona do "baixo meretrício" é o objeto do artigo "Entre o sagrado e o profano: identidades, paradoxos e ambivalências de prostitutas evangélicas do baixo meretrício de Belo Horizonte", de Jefferson Rodrigues Pereira, José Vitor Palhares dos Santos, Alice Gerlane Cardoso da Silva, Kely Cesar Martins de Paiva e Alexandre de Pádua Carrieri.

Nesta edição, contamos ainda com um artigo convidado, "Liderança feminina: percepções, reflexões e desafios na administração pública", escrito por Renata Kessler Miltersteiner, Fátima Bayma de Oliveira, Lygia Gonçalves Costa Hryniewicz, Anderson de Souza Sant'Anna e Luiz Carlos Moura, cujo objetivo é melhor compreender os desafios enfrentados na ocupação de posições de liderança por mulheres da administração pública do executivo brasileiro.

Concluindo a apresentação desta edição, apresentamos a resenha bibliográfica "O livro proibido de Guerreiro Ramos", a qual versa sobre Mito e verdade da revolução brasileira, em que Guerreiro Ramos critica as raízes do stalinismo, apontando os desafios da transformação do Brasil contemporâneo.

Boa leitura!

Prof. Dr. Hélio Arthur Reis IRIgaray

EDITOR-CHEFE 


\section{REFERÊNCIAS}

CÂNDIDO, M. R.; CAMPOS, L. A. Blog Dados, 14 maio 2020. Disponível em: <http://dados.iesp.uerj.br/pandemia-reduz-submissoes-demulheres/>. Acesso em: 20 maio 2020.

CONFEDERAÇÃO NACIONAL DA INDÚSTRIA - CNI. Três em cada quatro brasileiros vão manter redução de consumo após a pandemia. Agência CNI de Notícias, Brasília, 07 maio 2020. Disponível em: $<$ https://noticias.portaldaindustria.com.br/noticias/economia/tresem-cada-quatro-consumidores-vao-manter-reducao-no-consumono-pos-pandemia/>. Acesso em: 07 maio 2020.

FUNDO MONETÁRIO INTERNACIONAL-FMI. World Economic Outlook Reports: The Great Lockdown. 2020. Disponível em: <https://www. imf.org/en/Publications/WEO/Issues/2020/04/14/weo-april-2020>. Acesso em: 20 maio 2020.

HAN, B. C. A Sociedade do Cansaço. Rio de Janeiro: Editora Vozes, 2019.

HE, F.; DENG, Y.; LI, W. Coronavirus Disease 2019: What We Know? J Med. Virol., Early view, p. 1-7, 2020. Disponível em: <https://doi. org/10.1002/jmv.25766>. Acesso em: 20 maio 2020.

INSTITUTO BRASILEIRO DE GEOGRAFIA E ESTATÍSTICA - IBGE. Pesquisa Nacional por Amostra de Domicílio Contínua - PNAD Contínua. 2020. Disponível em: <https://www.ibge.gov.br/estatisticas/sociais/ populacao/9171-pesquisa-nacional-por-amostra-de-domicilioscontinua-mensal.html>. Acesso em: 15 maio 2020.
LGBTIS vivem acirramento de violência familiar em isolamento social. Folha vitória, Espírito Santo, 17 maio 2020. Disponível em: <https://www.folhavitoria.com.br/ geral/noticia/05/2020/Igbtisvivem-acirramento-de-violencia-familiar-em-isolamento-so cial>. Acesso em: 20 maio 2020.

LISBOA, V. LGBTIs vivem acirramento de violência familiar em isolamento social. Agência Brasil, Rio de Janeiro, 17 maio 2020. Disponível em: <https://agenciabrasil.ebc.com.br/direitos-humanos/ noticia/2020-05/Igbtis-vivem-acirramento-de-violencia-familiar-emisolamento-social>. Acesso em: 17 maio 2020.

MIRANDA, A. R. A. et al. O exercício da docência universitária por docentes mulheres. Pretexto, Belo Horizonte, v. 14, n. 1, p. 106-123, 2013.

MODELLI, L. Violência física e sexual contra mulheres aumenta durante isolamento social provocado pelo coronavírus. G1, Rio de Janeiro, Seção Bem Estar, 19 abr. 2020. Disponível em: <https://g1.globo.com/ bemestar/coronavirus/noticia/2020/04/19/violencia-fisica-e-sexualcontra-mulheres-aumenta-durante-isolamento-social-provocadopelo-coronavirus.ghtml>. Acesso em: 16 maio 2020.

SINGHAL T. A. Review of Coronavirus Disease-2019 (COVID-19). The Indian Journal of Pediatrics, v. 87, n. 4, p. 281-286, 2020.

WORLD HEALTH ORGANIZATION - WHO. Novel Coronavirus 2020. 2020. Disponível em: <https://www.who.int/emergencies/diseases/ novel-coronavirus-2020>. Acesso em: 15 maio 2020.

Prof. Dr. Hélio Arthur Reis Irigaray

ORCID: https://orcid.org/0000-0001-9580-7859

Doutor e Mestre em Administração de Empresas pela FGV-EAESP e PUC-Rio, respectivamente; Bacharel em Economia pela University of Northern Iowa, EUA; Professor adjunto da FGV-EBAPE e do programa CIM - Corporate International Masters, da Georgetown University, Washington, EUA; Líder do tema Diversidade e Relações de Trabalho, na linha de Gestão de Trabalho (ANPAD). E-mail: helio.irigaray@fgv.br 